UDC 372.881.111.1

DOI: $10.17223 / 24109266 / 9 / 13$

\title{
TEACHING VIA WEBQUEST
}

\author{
E.M. Shulgina \\ National Research Tomsk State University (Tomsk, Russian Federation) \\ E-mail: modestovna2@gmail.com
}

\begin{abstract}
Webquest is an educational technology, with the help of which students of higher schools using Internet resources can learn more about the subject-matter. Webquest has the well-defined structure and is aimed at inquiry and cognitive activities of students. An experiment was conducted in two student groups to collate teaching using webquest with the traditional one. Despite the students of both groups had equal level of foreign language competence, and the control group with traditional instruction enjoyed the topic a lot, the experimental group showed better results. Obviously, a webquest-based technology led to significant progress in subject-matter understanding versus customary instruction.
\end{abstract}

Keywords: webquest; technology; traditional.

\section{Introduction}

Since the Internet constantly envelops an enormous part of human activities, the education environment is not the exception. University teachers are persistently searching innovative ways to involve their students in research activities. One of the appropriate approaches to make students investigate a problem under study is a webquest technology. A webquest is an inquiry-oriented activity in which most or all of the information the students explore and evaluate is drawn from the web [1].

Webquests prompt students to ask questions, focus on using information rather than searching for it, and look at material critically. There are two main types of the webquest: a short-term and a long-term webquest. Short-term webquests engage learners on tasks that require one or two class periods permitting students to study a large number of sources containing new information and understand them in order to solve the problem under investigation. Long-term webquests require more than three class periods; it depends on the amount of information necessary for analysis and complexity of the webquest. An academic goal of any webquest is acquisition of knowledge and its integration into a system of knowledge, as well as a deep analysis and transformation of the information obtained into a new certain comprehension [2].

Students analyze information given in the links offered by the teacher, change and renovate it in some way and demonstrate in-depth understanding of the material by creating a final product that others can react or respond to. 
According to T. March, the "scaffolding structure" of webquests allows students to transform new information and comprehend it better [3]. Tom March noted that the possibility for collaborative work helps students to know the subject better; teamwork is an important student skill for achieving goals both inside and outside of classrooms. Many teachers who are engaged with similar techniques consider the webquest as an effective pedagogical strategy because it motivates students' critical thinking and contextualizes learning in a way that was not previously possible [4].

\section{Methodology}

Two groups of second-year students with the major 'Geography and Tourism' were taken for an experiment. One group of students was chosen as a control group and another - an experimental one. The experiment was conducted at Tomsk state university and lasted for two weeks. The author developed a webquest and designed the details of the webquest activity in advance. The students of the control group were learning the subject in a traditional way, i.e. without using webquests, while the students of the experimental group should fulfill a webquest offered by the teacher. The class scheduling strategy for the university made it possible for students to have English classes twice a week. The students of the experimental group had an opportunity to study the problems stated in the webquest both in the university computer room and at home. The students of the control group should do the homework as well. The nature of the curriculum was such that the students of both groups could be engaged in the problems concerning modern trends in hospitality and tourism.

\section{Experiment}

The participants were 23 university students with the major 'Geography and Tourism', who were divided into two groups: control (C-group, 11 members) and experimental (E-group, 12 members). A 30-item pre-test was administrated to each student on the first day of the experiment. The teacher scored each test. The results of the pre-test showed that the average level of both groups was equal and corresponded to A2 level.

The subject-matter was "Globalization". The goal was to compile the general picture of globalization in the world and predict its possible consequences. The C-group was taught by the same teacher and studied the problem in a traditional way. They listened to the teacher, took notes, read books, and participated in discussions on the given topic. The teacher kept the students on topic almost all the class time. The E-group worked through the webquest. The webquest consisted of three stages: initial, role-based, and final.

The initial stage lasted two classes. The students worked individually with the internet resources offered by the teacher. The webquest unit consisted 
of a web site containing a collection of web-based resources for exploration. The webquest contained a scoring rubric with detailed information on the teacher's requirements and expectations for their final product, a Power Point presentation. The teacher was also in the computer class assuring that students stayed on task, occasionally interacting with them and answering questions related to the webquest activities. She answered students' questions regarding the topic.

The role-based stage lasted one class. The students were divided into three subgroups according to the roles: subgroup I - 'centralization of management', subgroup II - 'world financial market', and subgroup III - 'international tourism'. The participants worked in subgroups of four. Each subgroup chose a leader. In the course of working the leaders helped the students of their subgroups who experienced any difficulties with the language; in this case a process of self-training emerges, since the information transforms into deep comprehension due to the explanation.

The third stage, the final, took place in the fourth class. All students worked together. Their task was to create a presentation; they had to include all the information they had obtained and processed. The students' computer proficiency was high enough to create their final product and they experienced very few problems related to working with Power Point software. The other group also had to prepare an in-class presentation.

Moreover, at the end of two weeks, both groups of students were given a post-test that was identical to the pre-test. The post-test was scored by the teacher.

\section{Results}

In the experiment, the units under test were the students' competences: language, speech and cultural.

The experiment results were encoded for statistical treatment, which was conducted with the help of Microsoft EXCEL software. Indices for each component were encoded and evaluated in a three-point scale: "0" - low level, " 0.5 " - average level, " 1 " - high level. If an answer testified the student's ignorance about a certain aspect, it was evaluated as " 0 ". If a student demonstrated certain knowledge of the subject but experienced some difficulties or answered with the help of prompting questions, his / her answer was evaluated as " 0.5 ". Finally, if a student's answer testified complete understanding of a subject-matter aspect, his / her answer was encoded as " 1 ".

For evaluation of statistical significance of the results we used Student's t-test. The Student's t-test is a test for statistical significance that uses tables of a statistical distribution called Student's t -distribution, which is that of a fraction $(t)$ whose numerator is drawn from a normal distribution with a mean of zero, and whose denominator is the root mean square of $\mathrm{k}$ terms drawn from the same normal distribution (where $\mathrm{k}$ is the number of degrees of freedom). 

formula:

In case of disconnected samples, t-test was evaluated according to the

$$
t=\frac{|\bar{x}-\bar{y}|}{S_{d}},
$$

where for equal samples $S_{d}=\sqrt{S_{x}{ }^{2}+S_{y}{ }^{2}}=\sqrt{\frac{\sum\left(x_{i}-\bar{x}\right)^{2}+\sum\left(y_{i}-\bar{y}\right)^{2}}{(n-1) n}}, x$ и $y$ - the results of testing students of both groups, $\bar{x}$ и $\bar{y}$ - average score, $n-$ number of tasks. The number of freedom degree: $k=2 n-2$.

In case of connected samples, t-test was evaluated according to the formula:

$$
t=\frac{\bar{d}}{S_{d}}
$$

where $\bar{d}=\frac{\sum d_{i}}{n}=\frac{\sum\left(x_{i}-y_{i}\right)}{n}, d_{i}=x_{i}-y_{i}\left(d_{i}=x_{i}-y_{i}\right.$ is a difference between appropriate value of the variable $x$ and the variable $y$, and $d$ is the mean product of the differences), and

$$
S_{d}=\sqrt{\frac{\sum d_{i}^{2}-\frac{\left(\sum d_{i}\right)^{2}}{n}}{(n-1) n}} .
$$

The number of freedom degree: $k=n-1$.

Table 1

Indices of competence levels in control and experimental groups at the beginning of the experiment (pre-test results)

\begin{tabular}{|l|c|c|c|c|c|}
\hline \multicolumn{1}{|c|}{ Competence } & $\begin{array}{c}\text { Control } \\
\text { group }\end{array}$ & $\begin{array}{c}\text { Experimental } \\
\text { group }\end{array}$ & t-test & $\mathrm{p} \leq 0.05$ & $\mathrm{p} \leq 0.01$ \\
\hline Language & 0.337 & 0.330 & 0.3 & 2.07 & 2.82 \\
\hline Speech & 0.259 & 0.265 & 0 & 2.06 & 2.78 \\
\hline Cultural & 0.351 & 0.380 & 0.5 & 2.18 & 3.05 \\
\hline
\end{tabular}

Language

competence

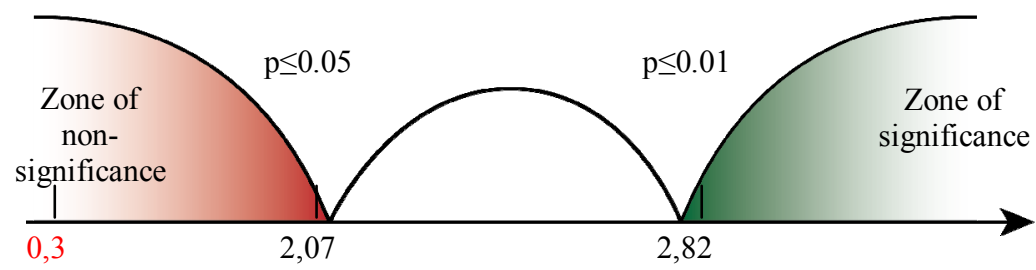


Speech

competence

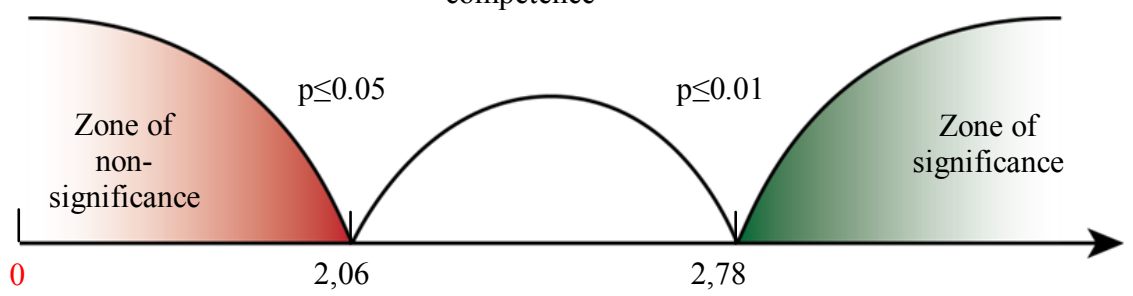

Cultural competence

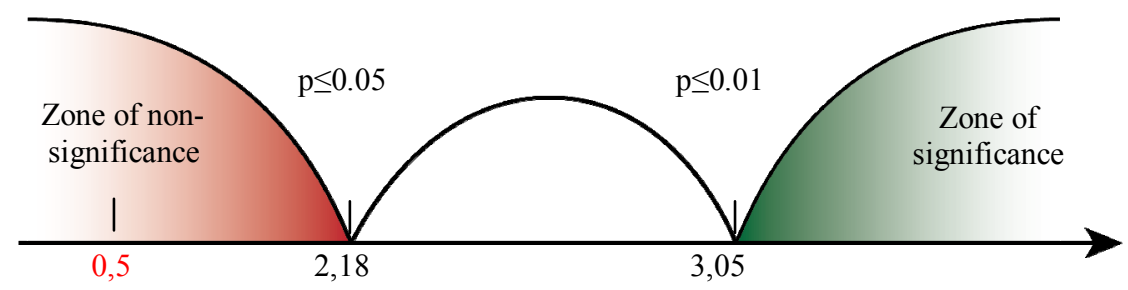

The empirical value $t-(0.3 ; 0 ; 0.5)$ at $5 \%$ level of significance (disconnected samples) showed an approximate equality of competences of students in both groups.

T a ble 2

Indices of competence levels in control and experimental groups at the end of the experiment (post-test results)

\begin{tabular}{|c|c|c|c|c|c|}
\hline Competence & Control group & Experimental group & t-test & $\mathrm{p} \leq 0.05$ & $\mathrm{p} \leq 0.01$ \\
\hline Language & 0.530 & 0.694 & 4 & 2.07 & 2.82 \\
\hline Speech & 0.487 & 0.726 & 4.8 & 2.06 & 2.78 \\
\hline Cultural & 0.539 & 0.827 & 7.3 & 2.18 & 3.05 \\
\hline
\end{tabular}

Language

competence

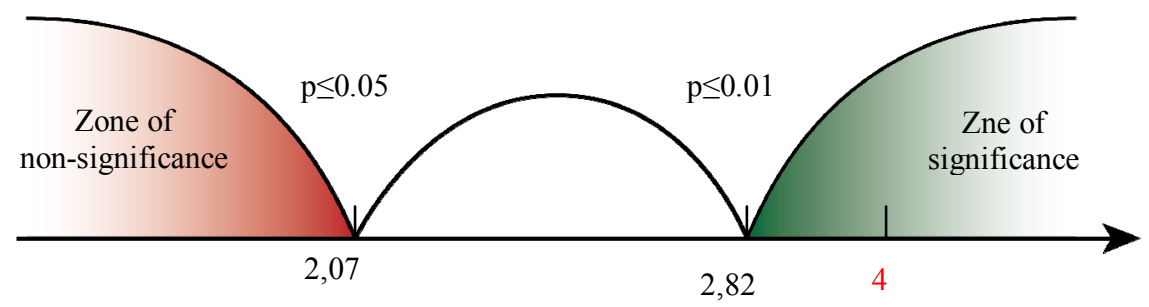


Speech competence

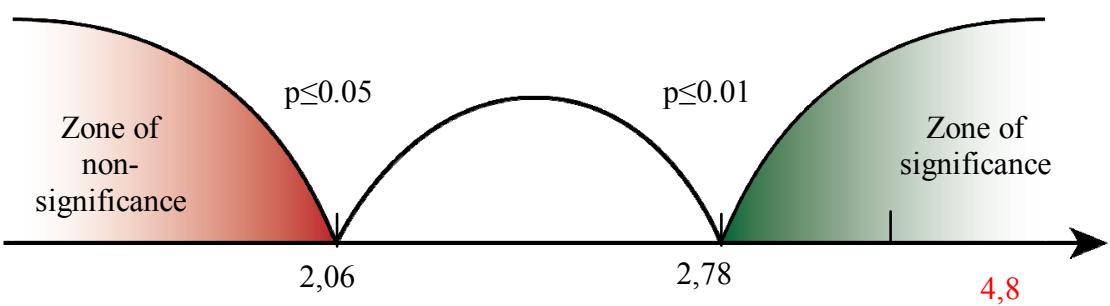

Cultural competence

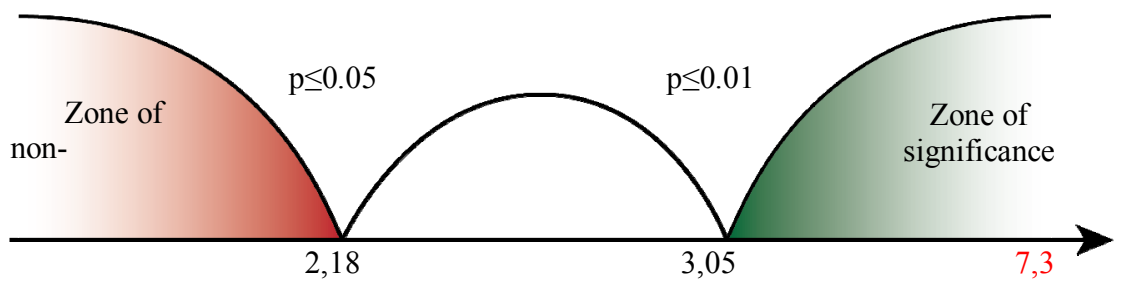

The empirical value t- $(4 ; 4,8 ; 7,3)$ at $5 \%$ level of significance (disconnected samples) showed an obvious increase of indices of competence level in both groups. However, the indices of the experimental group demonstrate significant progress versus the control group.

For visual evidence, we drew a diagram to show the difference between the indices of pre-test and post-test for both groups (fig. 1).

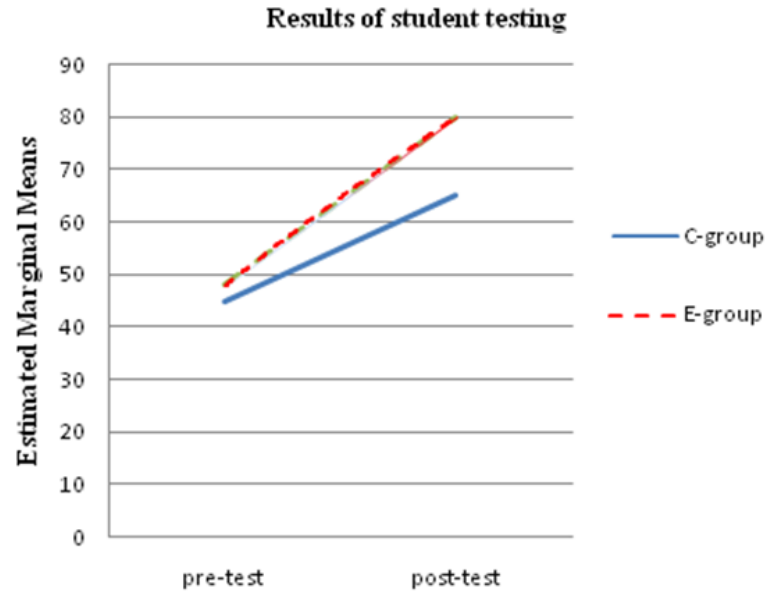

Fig. 1 
The post-test results at the end of the experiment showed that the webquest technology using in the educational process helps students to learn both individually, operating their cognitive and metacognitive processes, and in a team, solving problems together. In the result, the students of the experimental group have significantly increased their language competence level that is explicitly visible from the diagram above.

\section{Discussion}

The qualitative data suggest clearly that students had a positive attitude toward the webquest. On the fourth day of the experiment, the students of the experimental group were interviewed by the teacher. According to most interviews the students enjoyed learning through the webquest a lot. In response to initial, open-ended questions about the webquest, the students said:

Student 1: It was very detailed and interesting. I felt curiosity about the subject. I could draw much more information from the web than from a traditional lecture.

Student 2: I did a pretty good job. It was fun - I liked to do the quest. It was easier than just being in the classroom listening to the teacher the whole time...

Student 3: I think it was much more beneficial than learning in the classroom, but it was difficult because the language of the web-resources was too complicated. It was not fun but useful.

In this research, the author developed the webquest for the class and designed the details of the webquest activity. Also, the background was one with rich support for technology and in which admittance to hardware was trouble-free and levels of student intelligence with reference to technology use were high. It was clear that, despite these factors, neither the students nor the teacher in this study were accustomed to using webquest as teaching / learning activities.

A forceful aspect in this study was that for the experiment, both the pre-test and post-test were the same. So, any learning differences can be attributed to the treatment. There are many other issues, however. In the course of the experiment students were working together. Working in a team unavoidably raises the level of performance-based feedback received by the students.

\section{Conclusions}

Thus, the webquest technology integration into the educational process allows students to master the subject-matter much deeper, while a traditional way of knowledge acquisition often results in learning the material by heart in order to pass an examination. 
According to the results, the webquest technology allows students to develop:

- computer skills;

- speech competence;

- professional vocabulary;

- positive sense for learning;

- teamwork skills;

- critical thinking;

- interest in the culture of other countries;

- scope of knowledge;

- creative potential;

- strategy for material acquisition.

\section{Acknowledgements}

The author is grateful to Vyacheslav Zasedatel, a senior teacher of Distance Learning Institute at Tomsk state university, for his help with statistical analyses. This work was conducted under the aegis of National research Tomsk state university.

\section{References}

1. Dodge, B. (1997). Some thoughts about webquests. URL: http://www.edweb.sdsu.edu/ people/bdodge/Professional.html

2. Gural, S.K., Shulgina, E.M. (2015). Socio-Cognitive Aspects in Teaching Foreign Language Discourse to University Students. Procedia - Social and Behavioral Sciences. 200. pp. 3-10.

3. March, T. (1998). Why webquests?, an introduction. WebQuest for Learning Web site. URL: http:/www.ozline.com/webquests/intro.html

4. Vidoni, K.L., Maddux, C.D. (2002). WebQuests: Can they be used to improve critical thinking skills in students? Computers in the Schools. 19(1/2). pp. 101-117.

Resived 02.05.2017

\section{Information about the author:}

Shulgina Elena - Candidate of Pedagogical sciences, Associate Professor, acting as Head of the Department of the English language of natural sciences and physics-and-mathematical faculties of Foreign Languages; National Research Tomsk State University (Tomsk, Russian Federation). E-mail: modestovna2@gmail.com 